\title{
Investigating the Effect of Ergonomics on Employee Productivity: A Case Study of the Butchering and Trimming Line of Pioneer Food Cannery in Ghana
}

\author{
Robert Becker Pickson ${ }^{1 *}$, Stephen Bannerman1, Patience Obeng Ahwireng² \\ ${ }^{1}$ College of Economics and Management, Sichuan Agricultural University, Chengdu, China \\ ${ }^{2}$ Department of Business Administration, University of Professional Studies, Accra, Ghana \\ Email: *my selfpickson@y ahoo.com
}

How to cite this paper: Pickson, R.B., Bannerman, S. and Ahwireng, P.O. (2017) Investigating the Effect of Ergonomics on Employee Productivity: A Case Study of the Butchering and Trimming Line of Pioneer Food Cannery in Ghana. Modern Economy, 8, 1561-1574.

https://doi.org/10.4236/me.2017.812103

Received: March 16, 2017

Accepted: December 17, 2017

Published: December 20, 2017

Copyright (ङ 2017 by authors and Scientific Research Publishing Inc. This work is licensed under the Creative Commons Attribution International License (CC BY 4.0).

http://creativecommons.org/licenses/by/4.0/

\begin{abstract}
This study sought to investigate the effect of ergonomics on the employee productivity focusing on the Butchering and Trimming Line of Pioneer Food Cannery Limited (PFC) in Ghana. Research questionnaires were developed and distributed to a sample of 134 workers consisting of workers in charge of butchering, trimming as well as supervisors. It was evident from the findings that all the indicators explaining work ergonomics from the perspective of the employees of PFC were satisfactory despite the few respondents who indicated unsatisfactory to the general design and workplace décor, and conduciveness of the room temperature and air quality respectively. It was established that all the indicators of work ergonomics have a significant positive correlation with employee productivity of PFC. The study recommended to the management of Pioneer Food Cannery Limited to instigate a corporate real estate policy that will focus on using PFC workplace environment to attract, retain, and boost the performance of PFC employees.
\end{abstract}

\section{Keywords}

Work Ergonomics, Employee Productivity, Employee Satisfaction, Pioneer Food Cannery

\section{Introduction}

The workforce is the most valuable asset of any business and as such serious at- 
tention should be given to the workplace conditions which are prerequisites for improving productivity and quality of outcomes. According to Cole [1] as cited by Yankson [2], the fundamental factors that affect employee productivity and performance fall into two categories: management driven factors which include the development of organisational plans such as the allocation of responsibilities at all levels of the organisation, the definition of job descriptions and the degree of access to the management and administrative support needed to complete their tasks, working patterns, shift-working, break times, absence or holiday cover and health and safety policies, including the provision of training, development of safe working practices and the adequate supply of protective clothing and equipment.

The other factors that affect performance and productivity arise from the work premises, office or factory design, machinery and workshop tools, workspace availability, light intensity, weather, temperature ventilation, humidity, noise, vibration, hygiene and welfare facilities. A factory or a workshop is often configured to maximize employees' interaction, and collaboration becomes an integral part of every workday.

Empirically, Roelofsen [3] has established that improving the working environment leads to a reduction in the number of complaints and absenteeism, but it results in an increased productivity. However, working conditions in many organizations may present lack of safety, health and comfort issues such as improper lightening and ventilation, excessive noise and emergency excess (Leblebici, [4]). Employees working under undesirable workplace conditions might turn out to be less productive. This may be so as the employees have to contend with many hazards and other issues that endanger their safety such as excessive noise, operating on dangerous/complex machines and conditions that cause injury to employees (Yankson, [2]).

From the viewpoint of Yankson [2], accidents at the workplace keep on increasing, despite the fact that management and employees are making efforts to ensure safety in the workplace. In relation to the report from the Human Resource Department of Pioneer Food Cannery Limited in Tema (Ghana) as cited by Appiah [5], the company spends over 20 million Ghana Cedis annually for paying compensation to the workers' accidents and injuries and other administrative cost for workplace injuries. The report further indicated that the company was taken to court by a former employee for damages concerning non-payment of a workplace injury. This has a negative influence on the employee productivity as the employees are not motivated to do their best on the job in order to trigger high productivity.

This study, therefore, seeks to determine the extent to which the employees at the Raw Pack Section (Butchering and Trimming Line) are satisfied with the ergonomic features of Pioneer Food Cannery Limited (PFC), and also to assess the impact of work ergonomics on the productivity of PFC employees at the Raw Pack Section. 


\section{Review of Related Literature}

Several scholars have noted that many organisations have been trying new designs and techniques to construct factory or office buildings which can improve employee productivity, and as such attract more employees. As a result, some empirical studies have been carried out to assess the impact of work ergonomics on the productivity of the employees. Sundstrom et al. [6] used 2391 workers at 58 sites to examine disturbance by office noise in relation to environmental satisfaction, job satisfaction, and job performance ratings before and/or after office renovation. Slightly, more than half of the workers (54\%) indicated that they were bothered often by noise, usually by people talking and telephones ringing. In addition, it was found that disturbance by noise correlated with dissatisfaction with the environment and job, but not with self or supervisor-rated performance.

Banbury and Berry [7] in their study titled "office noise and employee concentration", employed eighty eight (88) employees at two sites to identify causes of disruption and potential improvements. Also, the authors scrutinized the amount of exposure the workers had to the noise in order to determine any evidence for habituation. In connection with the level of noise, the respondents were asked how they would improve their environment and to rate examples of improvements with regards to their job satisfaction and performance. The respondents expressed that their concentration was impaired by various components of office noise, especially telephones left ringing at vacant desks and people talking in the background. The results showed no evidence for habituation to these sounds.

Haynes [8] attempted to investigate the impact that office comfort has on office occupants' productivity. The study claimed that there is a linkage between the physical comfort of the office environment and the effect on the productivity of the office occupants. The author from his review literature established that there is enough evidence to buttress the claim that office comfort can affect productivity. However, it was revealed that there is no generally accepted definition of office comfort, and there is a clear lack of agreement as to how office comfort should be measured.

In Pakistan, Hameed and Amjah [9] investigated the impact of office design on employee productivity as a case of banking organisations of Abbottabad. The study used 31 bank branches of 13 banks to ascertain the relationship between office design and productivity. The results from the study exhibited that office design is a very important in terms of rising employee productivity. Comfortable and ergonomic office design was found to enhance employee performance. Saleem et al. [10] affirmed that office design is very vital in terms of enhancing employee productivity, and as such comfortable and contented office design influences the employees to increase their performance.

Productivity has a close relationship with the internal environmental quality (IEQ), but how to appraise office workers' productivity has always posed a chal- 
lenge to ergonomists. This case in point prompted Lan et al. [11] to ascertain the effects of air temperature on office workers' well-being, workload and productivity-evaluated with subjective ratings. The researchers deployed twenty one (21) volunteered participants in the laboratory experiment to investigate the effect of internal air temperature $\left(17^{\circ} \mathrm{C}, 21^{\circ} \mathrm{C}\right.$, and $\left.28^{\circ} \mathrm{C}\right)$ on productivity. The participants were exposed to computerized neurobehavioural tests in the laboratory during which their physiological parameters including heart rate variation (HRV) and electroencephalograph (EEG) were also measured. The researchers used several subjective rating scales to record participant's emotion, well-being, motivation and workload imposed by responsibilities. The result indicated that warm discomfort negatively influenced the respondents' well-being and increased the ratio of low frequency (LF) to high frequency (HF) of HRV. It was found that respondents had to exert more effort to maintain their performance and they also had lower motivation to do work in the moderately uncomfortable environment as the workload imposed by tasks increased. The findings showed that thermal discomfort caused by high or low air temperature had a negative influence on office workers' productivity.

Applying convenient sampling technique, Mak and Lui [12] considered 259 office workers in 38 air-conditioned offices to assess the impacts of sound on office productivity in Hong Kong. The study also determined the relationship between changes in office productivity and noise sources as well as five environmental and office design factors such as temperature, air quality, office layout, sound, and lighting. The results revealed that sound and temperature were the principal factors affecting the office productivity. Again, there appeared to be a strong and significant correlation between changes in office productivity and sound, temperature, and office layout. The study later used the mean productivity score of all respondents as a cut-off point to separate them into low-and high-productivity groups. It was found that noises from conversation, ringing phones and machines had a significant negative influence on all the respondents as there was a differed little in mean annoyance scores for the low- and high-productivity respondents. The study also discovered that noises such as background noise, closing doors, and human activity, as well as those coming from both inside and outside the office easily influenced low-productivity respondents. Evidence from the study suggested that sound has a major influence on office productivity in modern air-conditioned offices.

In the situation of Ghana, Asante [13] studied the impact of office ergonomics on employee performance with 98 employees of Ghana National Petroleum Corporation. Ergonomic elements such as office design, décor, illumination and noise levels and furniture were found to be negatively affecting the performance of employees by between $20-80$ percent. Also, few employees were found to have suffered musculoskeletal disorders which they attributed to their furniture. The researcher, therefore, asserted that Ghana National Petroleum Corporation was yet to leverage on its workplace environment as a means of motivating and enhancing the performance of its employees as the study identified substantial 
office ergonomic lapses.

Leblebici [4] considered 50 employees of a bank in Turkey to analyse the impact of workplace quality on employee productivity. The author evaluated the satisfaction of the employees towards the physical and behavioural environmental factors of the bank and found that employees were not satisfied with the physical factors which the bank has provided for them. However, the employee the satisfaction towards the behavioural environmental factors was recorded to be remarkably high. Findings from the study proved that workplace environment affects employee performance, whilst behavioural workplace environment has a greater effect on employee performance.

In a cross-sectional study, Jayaweera [14] assessed the relationship between work environmental factors and job performance with work motivation using 254 hotel workers in twenty five chain hotels in England. In addition, the study analysed the degree to which the relationship between elements of work environment and job performance is facilitated by work motivation. It was found that there is a significant relationship work environmental factors and job performance, and also noted that work motivation facilitates the association between working conditions and job performance. Also, work motivation was found to have a significant influence on job performance of the hotel workers. The findings indicated the importance of working conditions and work motivation in explaining the job performance of hotel employees in the framework of work environmental conditions and job performance.

\section{Study Methodology}

\subsection{Research Design}

Concerning the research design, the study employed descriptive survey method. A descriptive survey method is regarded as a type of quantitative research, which incorporates a careful description of a phenomenon in question beginning with a theoretical or applied research problem, and ends with empirical measurements and data analysis (Creswell, [15]). Its main purpose is to collect original data for describing or measuring the attitudes and orientation in a large population (Babbie, [16]). This method was relevant for this study in order to investigate the effect of ergonomics on employee productivity. The method was used because it allowed the researchers to ask many questions at one time, measure many variables, and test hypotheses in a single survey.

\subsection{Population and Sample Size of the Study}

The target population for this study involved all the employees of the Raw Pack Section (Butchering and Trimming Line) of the Pioneer Food Cannery Limited. They consisted of workers in charge of butchering, trimming and supervision. Thus, the target population of the study was estimated at one hundred and thirty four personnel (134) comprising fifty one (61) males and sixty three (73) who 
were at post during the period of the study.

According to Sauders et al. [17], for any research analysis to merit significance in statistical decision making, the sample size should be $10 \%$ or more of the population. However, considering the size of the target population for this study, the researchers intended to use all the one hundred and thirty four (134) staff of the Raw Pack Section of Pioneer Food Cannery Limited as the sample size for conducting this study. This again satisfies the condition needed for statistical test of significance in line with Oppenheim's [18] argument that a sample size must be $60 \%$ or more in order to warrant generalisation.

\subsection{Data Source and Method of Data Collection}

Primary data were used for this study. The primary data were obtained through the use of questionnaire adopted by Asante [13]. The content of the research instrument was validated by subjecting it to a review by experts in the field. This helped in obtaining a critical assessment of the instrument in terms of appropriateness and adequacy. The content of the instrument was equally cross-checked with the research objectives to ensure it covered all the areas of interest in the study. The questionnaires were later sent to all the Butchering and Trimming Line employees (Raw Pack Section) of Pioneer Food Cannery Limited with the aim of eliciting from them their responses on the impact of work ergonomics on the employee productivity.

\subsection{Data Analysis Methods}

Statistical Package for Social Sciences (SPSS) version 22; a research analysis tool was used to analyze the results of this research. With the help of this tool, frequency, percentage, and correlation were used for data presentation and analyses.

\subsection{Ethical Considerations}

In the conduct of this special study, the researchers took into cognizance the issues in research ethics to protect the interest of the respondents. The study commenced after the researchers sought the consent of the respondents. The respondents were informed about the purpose of conducting the study. The respondents were also told that they were free to end their involvement at any time during the study. The anonymity of research participants was guaranteed as the questionnaire did not bear any means that will identify any of the respondents. The study further analysed and interpreted the responses which formed the data without any link to a particular respondent. Confidentiality of the respondents was ensured by keeping data secured and using it only for the purpose of this study and its publication.

\section{Empirical Results and Analysis}

\subsection{Socio-Demographic Characteristics of Respondents}

The socio-demographic characteristics of respondents are presented in Table 1. 
Table 1. Socio-demographic characteristics of respondents.

\begin{tabular}{|c|c|c|c|}
\hline & & $\mathbf{N}$ & $\%$ \\
\hline \multirow{3}{*}{ Gender } & Female & 73 & 54.50 \\
\hline & Male & 61 & 45.5 \\
\hline & Total & 134 & 100.0 \\
\hline \multirow{5}{*}{ Age Group } & $20-29$ years & 37 & 27.60 \\
\hline & $30-39$ years & 60 & 44.80 \\
\hline & 40 - 49 years & 28 & 20.90 \\
\hline & $\geq 50$ years & 9 & 6.70 \\
\hline & Total & 134 & 100.0 \\
\hline \multirow{5}{*}{ Level of Education } & WASSCE & 112 & 83.60 \\
\hline & Ordinary Diploma & 12 & 9.00 \\
\hline & Higher National Diploma & 3 & 2.20 \\
\hline & First Degree & 7 & 5.20 \\
\hline & Total & 134 & 100.0 \\
\hline \multirow{6}{*}{ Length of Service } & $0-1$ year & 18 & 13.40 \\
\hline & $2-3$ years & 40 & 29.90 \\
\hline & $4-6$ years & 10 & 7.50 \\
\hline & $7-9$ years & 14 & 10.40 \\
\hline & $\geq 10$ years & 52 & 38.80 \\
\hline & Total & 134 & 100.0 \\
\hline
\end{tabular}

Source: Field Survey, 2016

\subsubsection{Sex Distribution of the Respondents}

The statistics shown in Table 1 indicates that $45.5 \%$ of respondents were males as against $54.5 \%$ of females. These percentages were gotten from 61 males and 73 females respectively. This made the study devoid of gender inequality. Therefore, sex of respondents was useful as the researchers were able to know the gender balance so as to make constructive analysis devoid of gender disparity.

\subsubsection{Age Distribution of the Respondents}

Table 1 illustrates the that most data collected from the field and the respondents who participated in the survey and responded to issues raised had the majority of them, thus 60 (44.8\%) between the age range of 30 - 39 years workers, this was followed not too closely by those who were between $20-29$ years forming 37 (27.6\%). Also, $28(20.9 \%)$ were within the age bracket of $40-49$ years, whereas workers within the bracket of 50 years and above were 9 representing $6.7 \%$. The age of respondents helped the researchers to differentiate between the different categories of respondents. Moreover, the majority of the respondents dominated by 30 - 39 years signifies that there are matured workers at the Raw Pack of Pioneer Food Cannery Limited and therefore decision-making is done effectively. 


\subsubsection{Level of Education}

The statistics in Table 1 shows the analysis of the levels of education of the respondents. It was found that 12 of the respondents constituting $9 \%$ were Ordinary Diploma holders, 2.2\% (3) were High National Diploma (HND) holders, and 7 of them constituting $5.2 \%$ were graduates. However, the study discovered also that $83.6 \%$ (112) of one hundred and thirty four (134) respondents were WASSCE holders. This implies that majority of the workers at the Raw Pack Section of Pioneer Food Cannery Limited are senior high school leavers.

\subsubsection{Length of Service}

Length of service in years is presented in Table 1 . The study discovered that 18 (13.4\%) of the respondents have spent between 0 - 1 year with the organization, $10(7.5 \%)$ of the respondents have worked for the PFC between $4-6$ years, 14 (10.4\%) of the respondents have served between 7 - 9 years, whilst 40 of the respondents have served PFC between 2 to 3 years representing 29.9\%. Also, 52 $(38.8 \%)$ of the respondents served the organisation for 10 years and above.

\subsection{Level of Employee Satisfaction with Work Environment}

Table 2 demonstrates the results of respondents' responses on their level of satisfaction with the work environment.

The study asked if the employees were satisfied with the general design and workplace decor. It was found that $7.5 \%$ of them were very satisfied with $32.8 \%$ disclosing satisfied. However, $44 \%$ and $15.7 \%$ stated dissatisfied and very dissatisfied respectively. This implies that most employees are not satisfied with the general design and décor of the Raw Pack Section of PFC. A little less than half (41.8\%) of the employees indicated that they were satisfied with the spatial arrangement and furnishing of their work environment with $11.2 \%$ indicating very satisfied. In contrast, $32.8 \%$ and $9 \%$ respectively were dissatisfied and very dissatisfied. Also, majority of the respondents (41\%) revealed that they were satisfied with the level of workplace flexibility and comfort whereas $32.8 \%$ disclosing very dissatisfied. However, $12.7 \%$ of them stayed indifferent. The respondents were also asked if they were satisfied with the size of space allocated for the Raw Pack section. Majority (38.8\%) of the respondents were satisfied whereas $15.7 \%$ dissatisfied. Also, $33.1 \%$ very satisfied whereas $10.4 \%$ very dissatisfied. In this present study, however, majority of the respondents (38.1\%) expressed that they were satisfied with the ease with which they could communicate and collaborate with their colleagues during work and $35.1 \%$ of them were very satisfied. On the contrary, $26.9 \%$ indicated that they find it difficult communicating and collaborating with their co-workers during work.

The state and suitability of workplace furniture as viewed as a very important factor to enhancing the health and productivity of employees in any organisation. The employees at the Raw Pack section of PFC were investigated to establish the extent to which they perceive the state and suitability of their section's furniture. Impressively, a significant statistic of $88.8 \%$ said they were satisfied 
Table 2. Level of employee satisfaction with work environment.

\begin{tabular}{|c|c|c|c|c|c|c|c|c|c|c|c|}
\hline & \multirow{2}{*}{ Workplace Elements } & \multicolumn{2}{|c|}{$\begin{array}{c}\text { Very } \\
\text { Satisfied }\end{array}$} & \multicolumn{2}{|c|}{ Satisfied } & \multicolumn{2}{|c|}{ Dissatisfied } & \multicolumn{2}{|c|}{$\begin{array}{c}\text { Very } \\
\text { Dissatisfied }\end{array}$} & \multicolumn{2}{|c|}{ Undecided } \\
\hline & & $\mathrm{N}$ & $\%$ & $\mathrm{~N}$ & $\%$ & $\mathrm{~N}$ & $\%$ & $\mathrm{~N}$ & $\%$ & $\mathrm{~N}$ & $\%$ \\
\hline- & $\begin{array}{l}\text { General design and } \\
\text { workplace décor. }\end{array}$ & 10 & 7.5 & 44 & 32.8 & 59 & 44.0 & 21 & 15.7 & 0 & 0.0 \\
\hline- & $\begin{array}{l}\text { Spatial Arrangement and } \\
\text { Furnishing. }\end{array}$ & 15 & 11.2 & 56 & 41.8 & 44 & 32.8 & 12 & 9.0 & 7 & 5.2 \\
\hline- & $\begin{array}{l}\text { Level of workplace flex- } \\
\text { ibility and comfort. }\end{array}$ & 15 & 11.2 & 55 & 41.0 & 3 & 2.2 & 44 & 32.8 & 17 & 12.7 \\
\hline- & $\begin{array}{l}\text { Size of space allocated for } \\
\text { your workplace. }\end{array}$ & 47 & 35.1 & 52 & 38.8 & 21 & 15.7 & 14 & 10.4 & 0 & 0.0 \\
\hline- & $\begin{array}{l}\text { Ease of communication } \\
\text { and collaboration. }\end{array}$ & 47 & 35.1 & 51 & 38.1 & 36 & 26.9 & 0 & 0.0 & 0 & 0.0 \\
\hline- & $\begin{array}{l}\text { State and suitability of } \\
\text { workplace furniture. }\end{array}$ & 46 & 34.3 & 73 & 54.5 & 7 & 5.2 & 8 & 6.0 & 0 & 0.0 \\
\hline- & $\begin{array}{l}\text { State of workplace } \\
\text { equipment. }\end{array}$ & 15 & 11.2 & 70 & 52.2 & 24 & 17.9 & 17 & 12.7 & 8 & 6.0 \\
\hline- & $\begin{array}{l}\text { Room temperature and } \\
\text { air quality. }\end{array}$ & 28 & 20.9 & 23 & 17.2 & 46 & 34.3 & 37 & 27.6 & 0 & 0.0 \\
\hline- & $\begin{array}{l}\text { Quality of } \\
\text { lighting-artificial lighting. }\end{array}$ & 60 & 44.8 & 62 & 46.3 & 6 & 4.5 & 6 & 4.5 & 0 & 0.0 \\
\hline- & $\begin{array}{l}\text { Level of noise from } \\
\text { speech, equipment, etc. }\end{array}$ & 55 & 41.0 & 31 & 23.1 & 24 & 17.9 & 24 & 17.9 & 0 & 0.0 \\
\hline
\end{tabular}

Source: Field Survey, 2016.

with the state and suitability of the furniture at their workplace. The study further asked to ascertain whether they were satisfied with the state of the equipment in the Raw Pack section. Slightly more than half (52.2\%) of the total respondents indicated that they were satisfied with the state of the equipment such as a mixer, sima seamer for canning, maja-deskinner, baader 523-squeezer, baader debonner, baader 52-deskinner, baader 200-splitting, and baader 427-deheader and $11.2 \%$ were very satisfied. Conversely, $17.9 \%$ and $12.7 \%$ of them showed their dissatisfaction and very dissatisfaction with the state of equipment respectively.

In responding to the statement as to whether they were satisfied with the room temperature and air quality, most respondents (34.3\%) indicated that they were dissatisfied and $27.6 \%$ very dissatisfied. However, $17.2 \%$ and $20.9 \%$ of them disclosed their satisfaction and very satisfaction respectively with this notion. On this premise, the study inquired whether they were satisfied with the quality of lighting-artificial lighting in the Raw Pack section of PFC. Majority of the respondents $(46.3 \%)$ said that they were satisfied and $44.8 \%$ being very satisfied with the quality of lighting-artificial lighting. On the contrary, $9 \%$ of the total respondents indicated their dissatisfaction with the quality of lighting-artificial lighting.

Noise level is one of the ergonomic elements that impacts employee communication and cognitive activities. The study, therefore, delved into finding out 
whether the workers were satisfied with the level of noise from speech, equipment, etc. Overwhelming (64\%) respondents admitted that they were satisfied with the level of noise from speech, equipment, etc. However, $17.9 \%$ of the respondents said that they were very dissatisfied with the level of noise from speech, equipment, etc., while $17.9 \%$ were also dissatisfied.

In all, the results indicated that employees at the Raw Pack Section of Pioneer Food Cannery Limited were satisfied with the general design and workplace décor, spatial arrangement and furnishing, level of workplace flexibility and comfort, size of space allocated for the workplace, ease of communication and collaboration, state and suitability of workplace furniture, state of workplace equipment, room temperature and air quality, quality of lighting (artificial lighting), and level of noise from speech and equipment. These findings confirm what other studies have established between employee satisfaction and work environment; for instance, Sundstrom et al. [6], Carayon and Smith [19], Van Der Voordt [20], Banbury and Berry [7], Steiner [21], and Miller et al. [22].

\subsection{Impact of Work Ergonomics on the Productivity of PFC Employees}

Table 3 presents Pearson's correlation analysis to investigate the relationship between workplace elements in the Raw Pack section of Pioneer Food Cannery Limited and employee productivity.

The results in Table 3 demonstrated that all the workplace elements the study asked respondents have a positive association with employee productivity of Pioneer Food Cannery Limited. The study indicated that there is a strong relationship $(r=0.741 ; \mathrm{P}<0.01)$ between general design and workplace decor and employee productivity, which is a characteristic of work ergonomics. The relationship was also significantly positive indicating that as an organization attends to its general design and workplace decor, it will also increase its employee productivity.

Table 3. Correlations between work ergonomics and employee productivity.

\begin{tabular}{|c|c|c|}
\hline & Workplace Elements & Employee Productivity \\
\hline- & General design and workplace décor. & $0.741^{\star \star}$ \\
\hline - & Spatial arrangement and Furnishing. & $0.803^{* *}$ \\
\hline- & Level of workplace flexibility and comfort. & $0.778^{* *}$ \\
\hline - & Size of space allocated for their workplace. & $0.352^{* *}$ \\
\hline - & Ease of communication and collaboration. & $0.398^{* *}$ \\
\hline - & State and suitability of workplace furniture. & $0.287^{\star \star}$ \\
\hline- & State of workplace Equipment (computers, etc). & $0.808^{\star \star}$ \\
\hline - & Room temperature and air quality. & $0.372^{\star *}$ \\
\hline- & Quality of lighting-artificial lighting. & $0.340^{* *}$ \\
\hline - & Level of noise from speech, equipment, etc. & $0.351^{\star *}$ \\
\hline
\end{tabular}

Note: ${ }^{* *}$ : Correlation is significant at the 0.01 level (1-tailed). Source: Field Survey, 2016. 
This finding is confirmed in previous studies by Roelofsen [3], Haynes [8], and Fawcett and Rigby [23] which suggested that there exists a positive and significant correlation between general design and workplace décor and employee productivity. Also, De Been and Beijer [24] posited that there is a high positive impact of workplace type on employee productivity.

The study also portrayed a positive relationship $(r=0.803)$ between spatial arrangement and furnishing and employee productivity, and the relationship was significant at $(\mathrm{P}<0.01)$. This implies that whenever the organization enhances its spatial arrangement and furnishing, it results in improving its employee productivity. Similar studies by Becker [25], Fawcett and Rigby [23], and Saleem et al. [10] have shown a significant positive association between spatial arrangement and furnishing, and employee productivity.

Again, a positive significant relationship $(\mathrm{r}=0.778 ; \mathrm{P}<0.01)$ was observed between employee productivity and the level of workplace flexibility and comfort, which is an element of work ergonomics. This implies that as the level of workplace flexibility and comfort is enhanced the corresponding increase in employee productivity is very crucial and significant. Previous studies by Haynes [8], Van Der Voordt [20], and Liang et al. [26] also confirm the result obtained.

The correlation coefficient of 0.372 and significant value of ( $\operatorname{Sig}=0.000: \mathrm{P}<$ 0.01 ) indicated that there is a weak relationship between the conduciveness of room temperature and air quality, and employee productivity. The test indicated that the relationship between the variables was positive indicating that as the management of Pioneer Food Cannery improves its conduciveness of room temperature and air quality, there is a corresponding increase in its employee productivity. This result confirms the studies conducted by Chan et al. [27], Lan et al. [11], Cui et al. [28], Zalejska-Jonsson and Wilhelmsson [29], Zen et al. [30], and Krishnamoorthy et al. [31] which indicated that conduciveness of air temperature and air quality has a significant positive influence on employee well-being, workload, and productivity.

Also, the sort of relationship that existed between the state of workplace equipment (such as mixer, sima seamer for canning, maja-deskinner, baader 523-squeezer, baader debonner, baader 52 deskinner, baader 200-splitting, and baader 427-deheader) and employee productivity was positive. This is not quite surprising because as it is observed empirically, there is always a strong positive relationship between the two variables and this study affirms previous empirical evidence. The relationship was again significant $(\mathrm{r}=0.808, \mathrm{P}<0.01)$. This finding is consistent with the study by Fulmer et al. [32] which found that the state of workplace equipment is more valuable in terms of enhancing employee productivity.

In addition, a weak significant positive relationship existed between the size of space allocated for their workplace, ease of communication and collaboration, state and suitability of workplace furniture, quality light-artificial lighting, the level of noise from speech, equipment etc, and employee productivity. This im- 
plies that as an organization strives in enhancing the size of space allocated for their workplace, ease of communication and collaboration, the state and suitability of workplace furniture, quality light-artificial lighting, and the level of noise from speech, equipment etc.; there is a corresponding positive improvement in its employee productivity. Hence, the findings obtained in this study are consistent with that of Chan et al. [27], Leblebici [4], Mak and Lui [12], Roelofsen [3], Zalejska-Jonsson and Wilhelmsson [29], and Halin et al. [33].

\section{Conclusions and Policy Recommendations}

This study sought to investigate the effect of ergonomics on the employee productivity focusing on the Butchering and Trimming Line of Pioneer Food Cannery Limited (PFC) in Tema, Ghana. Research questionnaires were developed and distributed to a sample of 134 workers consisting of workers in charge of butchering, trimming as well as supervisors. It was evident from the findings that all the indicators explaining work ergonomics from the perspective of the employees of PFC were satisfactory despite the few respondents who indicated unsatisfactory to the general design and workplace décor, and conduciveness of the room temperature and air quality respectively. The study further established that general design and workplace décor, spatial arrangement, level of workplace flexibility and comfort, size of space allocated for the Raw Pack Section, ease of communication and collaboration, the state and suitability of workplace furniture, state of workplace equipment, room temperature and air quality, quality of lighting-artificial lighting, and the level of noise from speech, equipment, etc. of work environment have a significant positive correlation with PFC employee productivity.

Premised on the findings, the following recommendations are made for consideration by PFC as a means of utilizing its workplace environment to motivate and enhance the productivity of its employees.

1) The management of Pioneer Food Cannery Limited needs to instigate a corporate real estate policy that will focus on using PFC workplace environment to entice, maintain, and increase the productivity of PFC employees (see Asante, [13]).

2) The employees should be made to undergo periodic training on workplace ergonomics issues such as correcting walking on the wet and slippery floors, proper standing posture, how to reduce stress and strains in repetitive work, and how to avoid injury and disorders at the workplace. The training is expected to enlighten employees on the subject to help employees contribute meaningfully to the development of ergonomic interventions.

\section{References}

[1] Cole, E.A. (2002) Personnel and Human Resource Management. 5th Edition, Biddles Limited, London.

[2] Yankson, E. (2012) The Effect of Health and Safety Standards on Productivity in Ghana Rubber Estates Limited. Unpublished Master's Thesis, Institute of Distance 
Learning, Kwame Nkrumah University of Science and Technology, Kumasi.

[3] Roelofsen, P. (2002) The Impact of Office Environments on Employee Performance: The Design of the Workplace as a Strategy for Productivity Enhancement. Journal of Facilities Management, 1, 247-264. https://doi.org/10.1108/14725960310807944

[4] Leblebici, D. (2012) Impact of Workplace Quality on Employee Productivity: Case Study of a Bank in Turkey. Journal of Business Economics and Finance, 1, 38-49.

[5] Appiah, S.O. (Undated) Management's Role in Ensuring Workplace Safety: The Situation in a Ghanaian Factory. https://www.academia.edu/8098521/Managements_Role_in_Ensuring_Workplace_ Safety_The_situation_in_a_Ghanaian_Factory

[6] Sundstrom, E., Town, J.P., Rice, R.W., Osborn, D.P. and Brill, M. (1994) Office noise, Satisfaction, and Performance. Environment and Behavior, 26, 195-222. https://doi.org/10.1177/001391659402600204

[7] Banbury, S.P. and Berry, D.C. (2005) Office Noise and Employee Concentration: Identifying Causes of Disruption and Potential Improvements. Ergonomics, 48, 25-37. https://doi.org/10.1080/00140130412331311390

[8] Haynes, B.P. (2008) The Impact of Office Comfort on Productivity. Journal of Facilities Management, 6, 37-51. https://doi.org/10.1108/14725960810847459

[9] Hameed, A. and Amjad, S. (2009) Impact of Office Design on Employee Productivity: A Case Study of Banking Organizations of Abbottabad, Pakistan. Journal of Public Affairs Administration and Management, 3, 1-13.

[10] Saleem, A., Shah, A., Zaman, K., Arif, M., Shehzad, K. and Ullah, I. (2012) The Impact of Interior Physical Environment on Academicians' Productivity in Pakistan Higher Education Institutes Perspectives. Iranian Journal of Management Studies (IJMS), 5, 25-46.

[11] Lan, L., Lian, Z. and Pan, L. (2010) The Effects of Air Temperature on Office Workers' Well-Being, Workload and Productivity-Evaluated with Subjective Ratings. Applied Ergonomics, 42, 29-36. https://doi.org/10.1016/j.apergo.2010.04.003

[12] Mak, C.M. and Lui, Y.P. (2012) The Effect of Sound on Office Productivity. Building Services Engineering Research and Technology, 33, 339-345. https://doi.org/10.1177/0143624411412253

[13] Asante, K. (2012) The Impact of Office Ergonomics on Employee Performance; A Case Study of the Ghana National Petroleum Corporation (GNPC). Unpublished Master's Thesis, Institute of Distance Learning, Kwame Nkrumah University of Science and Technology, Kumasi.

[14] Jayaweera, T. (2015) Impact of Work Environmental Factors on Job Performance, Mediating Role of Work Motivation: A Study of Hotel Sector in England. International Journal of Business and Management, 10, 271-278. https://doi.org/10.5539/ijbm.v10n3p271

[15] Creswell, J.W. (2013) Research Design: Qualitative, Quantitative, and Mixed Methods Approaches. Sage Publications, Thousand Oaks, California.

[16] Babbie, N. (2005) Qualitative Evaluation Methods. Sage Publications, Beverly Hills.

[17] Saunders, M.N., Lewis, P. and Thornhill, A. (2007) Research Methods for Business Students, 5/E. Pearson Education India.

[18] Oppenheim, A.N. (2000) Questionnaire Design, Interviewing and Attitude Measurement. Bloomsbury Publishing.

[19] Carayon, P. and Smith, M.J. (2000) Work Organization and Ergonomics. Applied Ergonomics, 31, 649-662. https://doi.org/10.1016/S0003-6870(00)00040-5 
[20] Van Der Voordt, T.J. (2004) Productivity and Employee Satisfaction in Flexible Workplaces. Journal of Corporate Real Estate, 6, 133-148. https://doi.org/10.1108/14630010410812306

[21] Steiner, J. (2006) The Art of Space Management: Planning Flexible Workspaces for People. Journal of Facilities Management, 4, 6-22. https://doi.org/10.1108/14725960610644195

[22] Miller, N., Pogue, D., Gough, Q. and Davis, S. (2009) Green Buildings and Productivity. Journal of Sustainable Real Estate, 1, 65-89.

[23] Fawcett, W. and Rigby, D. (2009) The Interaction of Activity, Space and Cost Variables in Office Workstation Sharing. Journal of Corporate Real Estate, 11, 38-51. https://doi.org/10.1108/14630010910940543

[24] De Been, I. and Beijer, M. (2014) The Influence of Office Type on Satisfaction and Perceived Productivity Support. Journal of Facilities Management, 12, 142-157. https://doi.org/10.1108/JFM-02-2013-0011

[25] Becker, F.D. (1981) Workspace, Creating Environments in Organizations. Praeger Publishers.

[26] Liang, H.H., Chen, C.P., Hwang, R.L., Shih, W.M., Lo, S.C. and Liao, H.Y. (2014) Satisfaction of Occupants toward Indoor Environment Quality of Certified Green Office Buildings in Taiwan. Building and Environment, 72, 232-242. https://doi.org/10.1016/j.buildenv.2013.11.007

[27] Chan, E.H., Lam, K.S. and Wong, W.S. (2008) Evaluation on Indoor Environment Quality of Dense Urban Residential Buildings. Journal of Facilities Management, 6, 245-265. https://doi.org/10.1108/14725960810908127

[28] Cui, W., Cao, G., Park, J.H., Ouyang, Q. and Zhu, Y. (2013) Influence of Indoor Air Temperature on Human Thermal Comfort, Motivation, and Performance. Building and Environment, 68, 114-122. https://doi.org/10.1016/j.buildenv.2013.06.012

[29] Zalejska-Jonsson, A. and Wilhelmsson, M. (2013) Impact of Perceived Indoor Environment Quality on Overall Satisfaction in Swedish Dwellings. Building and Environment, 63, 134-144. https://doi.org/10.1016/j.buildenv.2013.02.005

[30] Zen, I.S., Ahamad, R. and Omar, W. (2014) The Development and Measurement of Conducive Campus Environment for Universiti Teknologi Malaysia (UTM) of Campus Sustainability. Jurnal Teknologi, 68, 73-84. https://doi.org/10.11113/jt.v68.2360

[31] Krishnamoorthy, A., Kronenburg, M.A., Shetterly, D.R. and Gaillard, F. (2016) Exploring the Relationship between Indoor Work Environment and Employee Perception of Health-Related Symptoms in an Office Environment. International Journal of Management Research and Reviews, 6, 44-58.

[32] Fulmer, I.S., Gerhart, B. and Scott, K.S. (2003) Are the 100 Best Better? An Empirical Investigation between Being a "Great Place to Work" and Firm Performance. Personnel Psychology, 56, 965-993. https://doi.org/10.1111/j.1744-6570.2003.tb00246.x

[33] Halin, N., Marsh, J.E., Hellman, A., Hellström, I. and Sörqvist, P. (2014) A Shield against Distraction. Journal of Applied Research in Memory and Cognition, 3, 31-36. https://doi.org/10.1016/j.jarmac.2014.01.003 